\title{
Correlação entre a Política Social e a Demográfica
}

\section{Estanislau Fischlowitz}

\section{BASES DEMOGRÁFICAS DA POLÍTICA SOCIAL}

E mente, deixar de tomar em consideração as bases demográficas da população a que se devem aplicar as suas realizações.

Tentaremos, pois, passar em revista os elementos estatísticos e dinâmicos do panorama populacional, procurando destacar as suas principais caracteristicas que oferece o Brasil, merecedoras da particular atenção sob o ponto-de-vista político-social.

\section{A. Pirâmide Populacional}

O que tem que ser, preliminarmente, examinado, como fundamento natural da política social, é a pirâmide populacional de um determinado país, que se nos apresenta numa determinada época:

Como é natural, a fôrça de trabalho disponivel - base natural da riqueza nacional - encontra seus limites objetivos, antes de mais nada, nos grupos existentes da população, capazes, dada a sua idade, a prestar trabalho produtivo a serviço da economia.

Em função das variáveis exigências de trabalho físico, intelectual e misto, relacionadas, por sua vez, com as condições tecnológicas e organizacionais das atividades primárias (lavoura, atividades extrativas minerais e florestais), secundárias (produção manufatureira) e terciárias (comércio, atividades bancárias e securitárias, serviços pessoais, administração pública, etc.), o limite etário minimo e máximo, em que se enquadra a faixa dos virtualmente ativos econômicamente, pode ficar sujeito, com o tempo, a alterações consideráveis .

Diga-se, desde já, que de um modo geral, os requisitos inerentes aos processos atuais de trabalho, cada vez mais mecanizado e simplificado, poderão contribuir para ampliar, com o correr do tempo, simultâneamente, «de cima» $e$ «de baixo» o grupo de pessoas aproveitáveis em atividades econômicas.

Temos que aceitar, todavia, essa impressão intuitiva com certa cautela. Com efeito, nas sociedades ultracapitalistas, subordinadas à orientação ex- 
tremada produtocrata, em que se observa e pratica quase religiosamente os conceitos da campanha de produtividade, apresenta dificuldades consideráveis à consecução do emprêgo para as pessoas acima de 50 ou menos de 40 anos, portanto de grupos de idade em que não se pode ainda notar a queda dos niveis de rendimento. Tal situação verifica-se sobretudo nos Fstados Unidos. A posição precária no mercado de trabalho das pessoas enquadradas nesses grupos etários constitui ali um dos mais graves pro blemas sociais. Vale a pena destacar que êsse problema tenha constituido objeto principal da mensagem presidencial de EISENHOWER promulgada por ocasião do Dia do Trabalho de 1957 . Essa situação resulta, ao que parece, também, da aguda concorrência da mão-de-obra jovem e adulta no mercado de trabalho, agravada pelo volumoso desemprêgo.

Seja como fôr, a pirâmide populacional existente tem que ser discriminada rigorosamente em três categorias:

a) os menores de idade (infância e mocidade), fisicamente incapazes ao trabalho, de acôrdo com as condições técnicas e organizacionais existentes na economia e os conceitos sociais, morais e legais, que prevalecem nesse particular - a base dessa pirâmide;

b) os grupos de idade média, de cujos componentes se recruta, potencialmente, a forç̧a de trabalho; e, enfim,

c) as classes de idade avançada, com capacidade acentuadamente reduzida ou nula de trabalho - «cume da pirâmide».

É extremamente importante tanto sob o prisma econômico como social, a proporção numérica entre a classe de econômicamente ativos (grupo b) e as camadas de econômicamente inativos (grupos a $e$ c).

Com efeito, é a grupo «médio», o produtivo que tem que sustentar com os resultados de seu trabalho ambas outras camadas, exclusiva ou preponderantemente, «consumidoras». Isto, for si só, limita, em têrmos econômicos, a amplitude e a profundidade das realizações sociais orientadas no sentido de proporcionar maior amparo aos grupos «improdutivos» da sociedade: educação e assistência à infância e à adolescência, assim como a manutenção das categorias de idade provecta.

É natural que a orientação, a intensidade e last but not least, o custeio das providências da politica social que beneficiam êsses dois grupos, incontestàvelmente merecedores de sua particular atenção, não podem deixar de depender da composição quantitativa dos mesmos.

Antes de submeter ao ligeiro exame os problemas específicos de natureza politico-social que se apresentam no Brasil, em relação ao grupo «baixo» e «altc» da pirâmide populacional, convém esboçar as particularidades da composição etária da população dêste país, que ressaltam da sua comparação com as caracteristicas dos demais povos, de civilização adiantada.

Com efeito, de acôrdo com o Prof. Giorgio Mortara («Aspectos Econômicos da Composição por Idade da População do Brasil» - Revista Brasileira de Estatistica, Julho/Dezembro de 1957), a população brasileira 
- em confronto com a população de vários outros países que interessam sobremodo para fins comparativos - distribui-se do seguinte modo em três grandes classes de idade:

IDADE (ANOS) — DISTRIBUIÇÃo PERCENTUAL

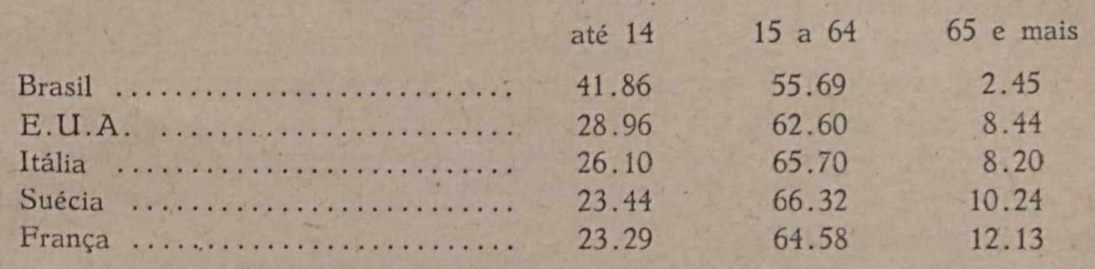

Como dai resulta, o panorama brasileiro demonstra a prevalência dos grupos de menor idade, a freqüência limitada dos grupos de idade avançada e a relativa paridade dos grupos de idade média.

O Nordeste é uma espécie de espelho côncavo em que os aspectos patclógicos do panorama brasileiro aparecem sob uma forma ainda muito mais distorta, mais afastada da norma. Assim, os grupos das idades infantis e juvenis ( 0 a 14 anos) chegam a atingir $44.16 \%$ e os grupos senis (de 60 anos e mais) representam uma parcela infima de $4.50 \%$, sendo que a fercentagem da população que proporciona a fôrça de trabalho não ultrapassa de $51.34 \%$, sendo que em alguns Estados, como no Piauí, no Ceará e em Sergipe não excede de $50 \%$. Para êsse efeito contribuem, além das condições econômicas e scciais notórias, também os fortes movimentos de emigração de proveniência dessa zona, de que participam sobretudo os enquadrados nos grupos etários médios. A gravidade social do panorama nordestino ressalta com ainda maior fôrça se se toma, outrossim, em consideração, por um lado, a indiscutivel superpovoaçãó e extrema densidade populacional daquela região e, por outro lado, a incidência acentuada da desemprêgo e subemprêgo - apesar da relativa escassa fôrça de trabalho em potencial, evidenciada pela estrutura etária acima indicada.

\section{B. Problemas Sociais que apresentam as «Bases» e o «Cume» dessa} Pirâmide: os Jovens e os Velhos

Vejamos agora quais problemas enfrenta a politica social nacional em relação ao primeiro e ao segundo dêsses grupos.

No que diz respeito ao primeiro dêles, cumpre, antes de mais nada, determinar o limite minimo de admissão ao trabalho (proibição do trabalho infantil) e regulamentar, a seguir, as condições do exercício do trabalho pelos menores de idade acima dêsse limite e abaixo da idade presumivel de maturidade, física e intelectual.

Essas tarefas incumbem, dentro dos preceitos constitucionais, à legislaçâo protetora do trabalho.

São óbvias as idéias que inspiram êsse mais antigo setor das realizações tutelares. Considera-se necessário proteger o organismo dos jovens 
e adolescentes, cujo desenvolvimento possa ser prejudicado pelo dispêndio dos excessivos esforços físicos. Julga-se indispensável evitar tudo o que possa entravar a educação dos menores. Enfim, procura-se prevenir os perigos de ordem moral, inseparáveis de seu ingresso não devidamente disciplinado na vida econômica ativa, com a possível evasão do lar familiar.

Como é notório, a Carta Magna proibe no art. 157, Inc. IX, o trabalho dos menores de 14 anos e a Consolidação das Leis do Trabalho dedica no Titulo III, Capítulo IV, a maior atenção à regulamentação das condições de trabalho dos menores de 18 anos (admissão ao emprêgo, duração do trabalho, aprendizagem, condições higiênicas e ambientais, em geral, do trabalho, etc.); enfim, no Título I, Capítulo III, estende as vantagens de salário-mírimo ao menores de idade.

Enveredando por êsse caminho, é, porém, preciso evitar rigorosamente quaisquer exageros, pois uma regulamentação excessiva demais poderia afetar a posição econômica das famílias de rendimentos limitados, em cujo orçamento as rendas do arrimo da familia não bastam, com freqüência, para ocorrer às despesas com a manutenção da numerosa prole, tornando imperioso a recurso às rendas complementares dos filhos.

O que é ainda mais grave, o afastamento dos menores das atividades econômicas perde tôda a sua razão se não se lhes proporciona, simultâneamente, recursos de educação geral ou profissional.

Destarte expõe-se a mocidade aos riscos de compulsória ociosidade, de mendicância e vadiagem, de delinqüência juvenil.

Suponhamos, todavia, que não haja deficiências escolares, infelizmente, ainda muito comuns no Brasil, e responsáveis pelos altos coeficientes de analfabetismo. O pré-requisito elementar da solução razoável seria fixar o limite minimo da idade de admissão ao trabalho assalariado de modo que possa coincidir com o limite máximo de atendimento escolar obrigatório. Assim, uma vez terminado o curso de ensino elementar, o jovem poderia passar imediatamente a exercer trabalho remunerado. O que, porém, ocorre é o diametralmente oposto: o chamado «hiato nocivo», que resulta da descoordenação da legislação escolar e trabalhista, sendo que a primeira sanciona o limite de 12 anos, e a segunda o de 14 anos. Como é que deve ser preenchida essa lamentável lacuna: dois anos de vida, sem visiveis oportunidades de utilização proveitosa dêsse período? Assinalamos a existência dêsse angustiante problema que, aliás, não escapou à atenção dos Podêres Públicos, sem podermos examinar nesșa altura as soluções que se cferecem a respeito.

Seja como fôr, as condições de trabalho e existência dessa enorme e relevante parcela da população e as possibilidades que se lhes oferecem no mercado de trabalho parecem merecer tratamento preferencial nas realizações da Previdência Social, da assistência social (Legião Brasileira de Assistência), dos serviços sociais, etc., mesmo fora das referidas medidas protetoras da legislaçãa tutelar. lacional.

Problemas nìtidamente diferentes apresenta o cume da pirâmide popu- 
Como é natural, não existe uma proibição paralela legal do trabalho acima de uma idade máxima; seriam arbitrárias quaisquer tentativas de determinaşão normativa de tal limite. Entretanto, admite-se que a Previdência Social e, particularmente, o seguro-velhice deve servir para (a) a absorção do grupo de idade avançada e de reduzida capacidade de trabalho, pernitindo seu afastamento dos contingentes de econômicamente ativos e (b) a renovação econômica e socialmente desejável dos quadros pessoais da economia mediante substituição dos trabalhadores velhos pelos jovens. Como é notório, os progressos de medicina acarretam a crescente longevidade média e aumentam a composição numérica dos grupos de idade maior. Por conseguinte, nota-se, pelo mundo afora, a tendência contrária a qualquer redução do limite de idade da aposentadoria-velhice cujos ônus crescem em tôda parte numa proporção considerável. No Brasil os processos de prorrogação da duração da vida humana e de incremento dos grupos de idade avançada não atingiram ainda o grau existente alhures, embora o próximo Censo de 1960 registrará, decerto, alguns progressos realizados nesse sentido. Entretanto, dada a existência da relativamente reduzida fração dos grupos etários médios que perfazem a fôrça de trabalho, parece duvidosa a justificação da recente redução a 55 anos do limite da aposentadoria-velhice e da elevação dos níveis dêsse benefício, que contribuirão para tirar da vida econômica, sem necessidade objetiva muito convincente, consideráveis contingentes de trabalhadores ainda válidos e fisicamente capazes ao trabalho.

Seja como för, em virtude das fortes pressões exercidas no mercado de trabalho pelos numerosos grupos da nova geração que todos os anos ingressam nesse mercado, em busca do primeiro emprêgo remunerado, é preciso facilitar com todos os meios ao alcance da política social a saída do exército de trabalko dos grupos de trabalhadores velhos e realmente inválidos ou de rendimento consideràvelmente reduzido; tais providências deveriam, em tese, abranger não sòmente a oportuna regulamentação da Previdência Social, inclusive o afastamento obrigatório do emprêgo, afastamento automática ou até por iniciativa patronal, dos trabalhadores admitidos à aposentadoria, uma vez atingidos, por exemplo, 60 a 65 anos de idade; e por outro lado, como nos quer parecer, o reexame dos atuais compromissos da chamada «estabilidade», instituto êsse de mais elevado alcance social, que, todavia, na sua forma atualmente vigente, dificulta muito ou até impossibilita a renovação dos quadros pessoais em relação aos trabalhadores que atingiram o período de dez anos de trabalho a serviço de uma deter minada emprêsa, mesmo se se revelassem improdutivos e pouco capazes ao trabalho, e se tivessem já adquirido direito a benefícios satisfatórios de seguro social (aposentadoria-velhice).

Diga-se de passagem que a organização da proteção e assistência às pessoas de idade avançada não se baseia, como é natural, apenas em considerações unilaterais de caráter populacional ou econômico.

Descansa em sólidos fundamentos éticos.

A sociedade que se respeita e preza não pode desprezar tudo o que deve aos pais e avós, devendo-lhes garantir, depois de labutarem durante longos anos e se sacrificarem pelos seus filhos e netos, niveis condizentes da 
existência, descanso bem merecido a que fazem plenamente jus. Apenas em algumas sociedades atrasadas não se reconhecem êsses direitos sagrados da velhice. Basta apcntar um exemplo flagrante: os costumes semi-selvagens dos esquimós que, premidos pelas condições de penúria alimentar - falta de carne - e sem meios de assegurar a subsistência de seus pais, levam-nos ao famigerado passeio de trenó, deixando-os, longe de suas habitações, no gêlo, onde morrem de frio...

Nessa digressão tivemos por objetivo desfazer a falsa impressão a que possa levar a análise dêsse problema limitada, por enquanto, exclusivamente, aos aspectos populacionais.

\section{Conseqüências da atual dinâmica populacional}

Nas considerações precedentes não prestamos ainda maior atenção aos fenômenos relacionados com as alterações que se verificam na dinâmica da população: seu crescimento, estagnação ou decréscimo. talidade.

Evidentemente, êsses processos dependem da natalidade e da mor-

Não nos parece, francamente, que tivessem sido descobertas as leis que regem a evolução demográfica. Às vêzes, não é fácil interpretar os surtos e declinios populacionais, procurando-se determinar com tôda a exatidão cientifica a sua origem.

Sem pretender abordar o exame pormenorizado dêsse assunto que nos afastaria da própria matéria dêste artigo, basta assinalar que assistimos no periodo de após-guerra ao enorme e quase generalizado incremento das pressões populacionais, um pouco, aliás, inexplicàvelmente atenuadas nestes últimos três anos.

Seja como fôr, aumentaram nos últimos lustros consideràvelmente os coeficientes de natalidade (número médio de nascimento por 1.000 habitanies) e, ao mesmo tempo, melhoraram muito as condições de sobrevivência, sobretudo em virtude da queda notável da mortalidade infantil e geral, que, por seu turno, resulta:

a) da vitória da medicina sôbre tôda uma série de doenças infecciosas, dos progressos relacionados com o uso de antibióticos e de outros recursos da medicina sanitária e terapêutica;

b) do maior acesso das classes populares a êsses recursos; e

c) das providências protetoras e assistenciais.

Qualquer que fôsse o fator principalmente responsável pela evolução nesse sentido: a maior fecundidade ou a menor natalidade, não pode ficar sujeito à contestação alguma o enorme ritmo de crescimento da população, que se verifica, particularmente nas partes subdesenvolvidas do mundo (Ásia) e nas classes menos favorecidas (a palavra "proletário» provém, como é notório, da numerosa prole peculiar das classes trabalhadoras), e que, constitui um dos principais problemas do mundo contemporâneo. 
Como reparou o Prof. Hersch Liebmann inaugurando a Conferência Demográfica Internacional realizada em Roma em 1954:

«O grande problema que preocupa os espiritos... é o crescimento extraordinàriamente rápido da população dos países econômicamente subdesenvolvidos, particularmente dos paises asiáticos».

Entre 1800 e 1900 a população mundial triplicou. De 185 mihões :m 1800, aumentou no século XIX de modo a atingir 530 milhões em 1900. Entre 1900 e 1950 , aumentou de 850 milhões.

Atualmente deve oscilar já em tôrno de 2 bilhões 800 milhões de habitantes. As previsões, as mais conservadoras possiveis, para o ano 2000 indicam a estimativa da população mundial igual a, pelo menos, 4 a 6 bilhões de habitantes.

\section{Maltusianos e Neomaltusianismo}

A primeira vista, pareceriam, assim, justificados os prognósticos da doutrina pessimista do pastor protestante Thomas RoBert MALthus (17601834) no seu conhecido ensaio sôbre os «Principios da População»-de 1798.

Convém recordar em breve as teses do maltusianismo. Malthus estava procurando demonstrar que a população cresce em proporção geométrica, cnquanto os meios de subsistência apenas em proporção aritmética.

O que dai deveria resultar fatalmente seria a supersaturação populacional dêste planêta, para cujo combate ofereceu vários meios de abstenção de casamentos no meio das classes populares, limitação da prole, etc. que, nas obras de seus epígonos: os neomaltusianistas do século XX vieram, com o tempo, assumir caráter cada vez mais drástico, mais anti-social e antimoral (métodos coercitivos no contrôle da natalidade, luta contra a medicina social e etc.).

Nas últimas décadas a doutrina maltusianista ressurgiu novamente das cinzas, com uma feição diferente da anterior, de orientação ecológica e biológica, nas obras de Fairfield Osborne, Lord Boyd Orr, Julian Huxley, Robert CoOK e William Vogt.

Esses estudiosos voltaram a sua precípua atenção para a produção de alimentos. Anotando que, de 1945 a 1952, a população do mundo aumentou de $12 \%$, enquanto a produção de gêneros alimentícios cresceu apenas de $9 \%$, tiraram dessa obșervação conclusões precipitadamente alarmantes, quanto ao perigo de supersaturação da população mundial, dado o suposto crescente hiato entre os podêres reprodutor humano e produtor alimentício, e, conseqüentemente, fome global.

Não podemos abordar aqui $\mathrm{cm}$ maiores detalhes a polêmica contra as teses neomaltusianistas e, sobretudo, contra as recomendações práticas, cuja orientação entra em flagrante choque com os preconceitos sociais e morais. Os dados estatísticos mais recentes demonstram, por si só, que os referidos desajustes parecem tender amenizar-se com o tempo.

Assim, segundo a FAO $(1934 / 38=100)$ a produção agrícola apresenta em 1954/55 indice de 127, enquanto a população igualmente de 127 . 
Se existe, realmente, distribuição desigual da população, do capital, das matérias-primas e dos alimentos, isto não quer ainda dizer que não se poderia conseguir muito melhor equilíbrio mediante movimentos de migração que, ora paralisados, poderão retomar, futuramente, maior intensidade. Não faltam ainda sempre enormes reservas de terra fértil não explorada, ou que o são de modo muito rudimentar. Seria inescusável derrotismo desprezar a enorme margem de aumento da alimentação que poderia oferece: a cultura cientifica, a adubação racional, o uso de inseticidas, o aproveitamento da ciência do sclo, a irrigação, a impermeabilização da lavoura contra os efeitos climáticos nocivos e vários outros métodos de elevação do rendimento agropecuário, independentemente da extração em maior escala da fauna marítima e da produção química-sintética dos alimentos. Com efeitc, parece mais que provável que no futuro não distante, como se nos possa afigurar no momento, será superada a fase atual do suprimento dos artigos de nutrição, baseada única e exclusivamente no aproveitamento das plantas e dos animais. Por outro lado, carece de justificativa a previsão de que continuará incondicionalmente intacto o atual ritmo particularmente forte de aumento de natalidade. Vários fatôres podem contribuir para paralisar a presente «explosão populacional». O conhecido autor nacional, Professor JosuÉ DE CASTRO, defende nas suas obras, aliás muito controvertidas e, particularmente, na «Geografia da Fome», a tese consoante a qual a fecundidade dependeria, principalmente, da subnutrição, tese essá corroborada por vários estudos biológicos recentes nos E.U.A. Assim, a elevação dos niveis de bem-estar social, lenta mas bastante generalizada, deverá repercutir sôbre a diminuição dos coeficientes de natalidade. Em outras palavras, de acôrdo com ALFRED SAUVY, ao lado da «solução demográfica», parece oferecer subsídios valiosos nesse sentido o que aquêle eminente cientista francês definiu como «a solução econômica».

Nas observações precedentes fizemos referência aos desequilibrios bastante acentuados na distribuição regional da população mundial. Contudo, é com certa cautela que temos que interpretar os têrmos corriqueiros de «paises superpovoados» e «subpovoados». A estimativa da sua respectiva densidade populacional, evidenciada pelo número de habitantes por $1 \mathrm{~km} 2$, não pode servir, por si só, para a devida apreciação da sua saturação demográfica, sobretudo se essas indicações não vêm sendo acompanhadas pela análise dos fatôres, estáticos e dinâmicos, de sua economia. Assim, por exemplo, a taxa relativamente moderada de habitantes por $1 \mathrm{~km} 2$ que se manifesta na Índia, comparada com a relativa escassez dos recursos valorizados daquele pais, é de molde de causar muito maior preocupação de que a sua incidência muito maior que encontramos na Holanda e Bélgica, todavia, com as suas economias nacionais incomparàvelmente mais desenvolvidas e capazes de sustentar seus aparentes excedentes populacionais.

Finalizando, convém tornar bem patente que, como ficou evidenciado pelas declarações do representante da Santa Sé na Conferência Demográfica Internacional em Roma de 1954, a Igreja não deixa de acompanhar com certa preocupação os problemas de «inflação populacional», dados seus possiveis efeitos prejudiciais com relação ao bem-estar social, sendo que apenas discorda das providências maltusianistas de combate ao crescimento da população mundial. 


\section{E. Relação entre a Politica Demográfica e Social}

O que nos interessa sobremodo sob o ponto-de-vista da matéria são, porém, as realizações da politica demográfica e a sua relação com a politica social.

A politica demográfica pode, em tese, visar alcançar dois objetivos diametralmente opostos: aumento ou redução da natalidade. O primeiro dêsses objetivos estava e continua ainda inspirando uma ampla gama de medidas tomadas pelos paises com potencial populacional ameaçado pela queda da natalidade, como por exemplo, a França. Considerações de outra natureza, relacionadas com a expansão imperialista e os preparativos para a agressão, de acôrdo com os princípios da doutrina nazi-fascista e racista, orientaram, por seu turno, as realizações dinâmicas da politica populacional (abonos familiares, subsídios de casamento, prêmios de natalidade, proteção às famílias, distinções honoríficas às mães com prole numerosa, etc.), levadas a efeito na Itália e na Alemanha no periodo compreendido entre 1922 e 1945.

Cumpre indagar se tais instrumentos, usados em mais ampla escala no intuito de promover a todo custo o incremento das taxas de natalidade, contribuiram, na realidade, para a consecução dêsse objetivo. Pois bem, de acôrdo com as observações judiciosas do Dr. Glass pode-se notar os subsídios palpáveis para tal efeito dessas providências apenas nos primeiros períodos, de duração muito limitada, depois de sua introdução. Com o tempo, a sua influência diminuiu muito, até perder, com o correr do tempo, qualquer «rendimento populacional». Cumpre assinalar êsse relativo fracasso das providências de ordem demográfica, à primeira vista surpreendente, sobretudo em vista da extrema amplitude e profundidade das mesmas, que chegaram ao ponto de assegurar aos chefes de familias numerosas vantaggens superiores às que possam conseguir com seu trabalho. Até hoje em alguns países como, particularmente, na França e na Itália, a reprodução fisiológica oferece a determinadas camadas da população maiores benefícios do que a produção; o trabalho assalariado na indústria...

Vejamos, por sua vez, a atuação dos instrumentos da política demográfica de orientação oposta, a «maltusianista», subordinados ao propósito de limitação da natalidade. Trata-se de uma experiência relativamente nova e de órbita territorial limitada quase exclusivamente aos países da Ásia (Japão, India e China), países de notória superpovoação.

Convém passar em revista as principais realizações nesse sentido.

No Japão foi introduzida, em junho de 1948, a «Lei Eugênica» com o propósito de estimular o uso dos contraceptivos, permitindo a interrupção da gestação em determinados casos de caráter social, higiênico e sanitário e autorizando, ao mesmo tempo, a esterilização temporária dos homens e das mulheres. Assistimos, naquele país, realmente a uma forte queda da natalidade (em 1948, 33,7 nascimentos por mil habitantes e, em 1957 apenas 17,5$)$, sem que se possa, todavia, formar idéia bastante clara a respeito da causalidade dessa evoluçăo e, particularmente, se deva ser atribuida - e eventualmente em que proporção - à influência daquela lei. 
Na China uma lei análoga, e que recorre aos mesmos meios de ação. acrescentados pela elevação da idade mínima para os casamentos, foi promulgada em março de 1957, com o propósito de conseguir, nos próximos dez anos, a redução de $50 \%$ no número total de nascimentos, atribuindo-se, aliás, na sua justificação, importância não sòmente a seus efeitos de caráter populacional, como também à proteção das mulheres e ao fortalecimento dos laços familiares.

Convém anotar iniciativas parecidas de contrôle da natalidade aplicadas, desde 1933, na Índia e, sobretudo, desenvolvidas em ampla escala na região de Bombaim. O segundo plano qüinqüenal (1956-61) destinou para êsse fim a importância de 50 milhões de rúpias. Não parecem, porém, por enquanto, muito convincentes os resultados práticos dessa campanha.

\section{F. Institutos Sociais de Proteção à Familia - Instrumentos da Politica Demográfica ou Social}

Procurando conceituar a política social, não podemos deixar de submeter a análise a sua correlação com as realizações da politica demográfica.

Acontece que vários institutos, criados com o propósito de incentivar o aumento da natalidade - dentro da primeira das duas correntes acimá expostas - podem servir também para a consecução das finalidades redistributivas da politica social mediante amparo econômico à família.

Não é possível interpretar devidamente as finalidades e funções sociais das referidas reformas, que constituem o mais recente, mas já extremamente expandido setor da legislação social, sem examinar, antecipadamente, os efeitos da composição da família sôbre a situação dos orçamentos comum no " meio das classes socialmente dependentes, de rendimentos parcos e estáveis.

Foi a famosa socióloga e politica trabalhista inglêsa Mrs. Eleanor RathBONE que definiu de um modo particularmente expressivo a essência dos problemas comparando as duas curvas:

a) a de rendimentos, e

b) a de gastos.

No orçamento típico proletário, com efeito, segundo a citada autora, a pobreza resulta nesse meio, em grande parte, da discrepância que se faz notar em certos períodos da vida do trabalhador, por um todo, entre:

a) seus rendimentos salariais mais ou menos estáveis e, por outra parte,

b) suas despesas que crescem consideràvelmente com o aumento numérico da família, para cair depois na proporção em que os gastos com os encargos familiares forem sendo compensados pelos rendimentos que o proporcione o trabalho dos filhos jovens e adolescentes - antes de constituírem seus próprios lares.

No seu famoso Relatório de 1944, dedicado ao Seguro Social e Serviços Correlativos, Sir William BEveridge atribui ao fator acima aludido a responsabilidade por $1 / 3-1 / 4$ dos casos de pobreza na sociedade inglêsa, sendo 
que o balanço caberia à inseguridade nas condições de existência das classes trabalhadoras, expostas ao impacto das contingências aleatórias: riscos biofísicos, físico-profissionais e econômicos. Foi dêsse diagnóstico que tirou conclusões quanto aos rumos da reforma de «Seguridade Social Integral» preconizada naquele Relatório, e extensiva ao abono familiar concedido a tôdas as famílias com mais de um filho menor, reforma essa posta em execução no Reino Unido em 1946.

O desamparo econômico da familia não leva apenas às graves conseqüências sociais. Com efeito, contribui, ao mesmo tempo, para a decomposição da família, celula mater da sociedade, sujeita aos efeitos corrosivos da civilização moderna, de novos estilos e modos de vida, das correntes ideológicas e morais prejudiciais que afetam a posição da familia, solapando a sua coesão e integridade.

A prematura evasão do lar dos menores, incapazes de satisfazerem às suas necessidades elementares de existência decente, é apenas um dos numeroses aspectos angustiantes da crise de familia. Tudo o que se possa, pois, fazer para restabelecer o equilibrio econômico da familia nos grupos menos favorecidos da população poderia reverter em benefício da consolidaçãa dos laços familiares. É, por conseguinte, sob êsse mais amplo prisma que têm que ser encaradas tôdas as providências subordinadas ao propósito de restabelecer o equilibrio econômico da família, ameaçado pelo atual sistema salarial com as suas peculiares regras distributivas niveladoras $e$ homogêneas, sem qualquer atenção voltada para os compromissos de sustento da familia.

\section{G. Compensação dos Encargus Familiares}

Quais são as técnicas que se oferecem para conseguir o objetivo acima aludido?

Não pode servir para êsse fim a discriminação das taxas salariais, de acôrdo com a existência e a extensão dos encargos familiares. Com efeito, tal solução levaria fatalmente, nas condições de economia de livre concorrência, a prejudicar a posição no mercado de trabalho dos trabalhadores casados e onerados por maiores compromissos de sustento da familia. Com efeito, caeteris paribus, os empregadores dariam, nessas condições, preferệncia a admissão ao emprêgo, aos trabalhadores solteiros que fariam jus ao salário inferior - em comparação com o engajamento daqueles q: te deveriam ser contemplados com remuneração superior.

É pela mesma razão que encontrou dificuldades consideráveis a diferenciação das taxas de salário-minimo, prevista no art. 157, Inc. I, da Constituição vigente ( «salário-minimo capaz de satisfazer, conforme as condições de cada região, as necessidades normais do trabalhador e de sua familia»). Eis uma das duas normas da parte da Constituição relativas à «Ordem Social» que se verificou, por enquanto, inexeqüivel, sem encontrar reflexo na legislação positiva em vigor...

Foi, pois, necessário procurar outras formas de solução que, mediante recurso à responsabilidade coletiva e não individual, a cargo dos empre- 
gadores isolados, possam contribuir para a consecução da finalidade almejada, sem os inconvenientes acima assinalados.

A primeira fórmula a que recorreu, nessa ordem de idéias, o patronato de vários países ocidentais (sobretudo França e Bélgica) no período posterior ao fim da primeira guerra mundial - periodo êsse caracterizado pela aguda inflação e forte carestia de vida, que evidenciou consideráveis dificuldades dos orçamentos familiares operários - foi a criação das «Caixas de Compensação e Supercompensação» de encargos familiares.

Mediante aplicação de vários métodos, mas sobretudo, por meio do pagamento das contribuições patronais que incidiam sôbre a fôlha total de salários, foram constituidos fundos especiais, distribuídos a seguir, sob a forma de «sôbre-salário familiar», aos trabalhadores que, dada a composição de suas familias, reuniam as condições aquisitivas predeterminadas nos respectivos regulamentos.

A dualidade de solução: Caixas de Compensação e Supercompensação foi justificada pelo compreensivel intuito de garantir a compensação daqueles ônus não apenas dentro dos limites estreitos de uma determinada emprêsa, mas, sim, dentro dos grandes ramos da indústria (como seja, por exemplo, a indústria têxtil, mecânica, e assim por diantę), o que assegura a mais ampla e harmoniosa distribuição dos respectivos encargos. Entretanto, com o tempo, verificaram-se alguns defeitos dessa solução, relacionados particularmente com a insuficiência das contribuições patronais, destinadas para êsse fin, com a amplitude limitada do seu respectivo âmbito pessoal, pois que, fora de sua órbita ficavam numerosos grupos de assalariados não filiados aos respectivos setores da indústria, e ainda vários outros inconvenientes práticos inseparáveis dessa fórmula - uma espécre de serviço social de caráter coletivo.

Nessas condições, vários paises passaram a procurar uma solução de outra indole, de caráter público ou paraestatal, que se enquadram no mecanismo do chamado «abono familiar».

O abono familiar no seu sentido técnico pròpriamente dito consiste na criação, mediante compromisso de direito público, de fundos especiais, aproveitados para contemplar com êsse benefício social sui generis as pessoas que arcam com os ônus de familia. As soluções legislativas que atualmente existem em, aproximadamente, 20 paises, apresentam uma ampla gama de regulamentações, sobratudo no que diz respeito aos seguintes aspectos:

$\left.1^{\circ}\right)$ Bases financeiras:

a) tributárias, quer dizer, financiamento pelo Estado com base no orçamento público, por conseguinte, com recursos aos impostos gerais; e

b) contributivas, isto é, contribuições ad hoc, a cargo do Estado, dos empregadores e dos trabalhadores, com variações que muito alteram as bases financeiras um para outro caso.

$2^{\circ} .^{\circ}$ Fundamentos organizacionais, intimamente relacionados com a bifurcação referida no item 1: órgãos governamentais na hipótese referida na letra (a), instituições previdenciais ou entidades especializadas paraestatais de natureza congênere na hipótese mencionada na letra (b). 
3..$^{\circ}$ Grupos dos beneficiados, mais uma vez em certa correlação com a dualidade das bases financeiras no item 1: concessão de abono familiar a todos os habitantes do país ou a todos os cidadãos na hipótese referida na letra (a) ou apenas aos trabalhadores assalariados - na hipótese mencionada na letra (b).

$\left.4^{\circ}\right)$ Amplitude dos encargos familiares que justifica a concessão do abono, isto é, faz jus ao abono o primeiro filho, ou apenas o segundo, o terceiro, etc., ou, enfim, apenas, a assistência à família numerosa.

$\left.5^{\circ}\right)$ Condições aquisitivas relacionadas, por exemplo, com o limite máximo de idade dos filhos que justifica a supressão do benefício (14 16 - 18 anos).

$\left.6^{n}\right)$ Modalidades que regem a forma dos «benefícios familiares»: capital global, pago de uma vez só, no momento do nascimento do filho ou prestações de caráter periódico, pagas mensalmente aos responsáveis pela manutenção dos filhos. E, enfim.

$\left.7^{\circ}\right)$ Numerosas outras particularidades individuais cuja enumeração escapa fatalmente a esta exposição sumária.

A primeira reforma pública nesse sentido foi levada a efeito na Nova Zelândia, pela lei promulgada em 1926.

Pois bem, no periodo dêstes últimos 33 anos, o abono familiar demonstrou uma expansáo impressionante, vertical e horizontal, acelerada pela introdução dêsse instituto na Inglaterra, dentro do plano de seguridade social beveridgiano, e a reforma análoga levada a efeito da U.R.S.S.

Os Estados Unidos da América do Norte são quase o único país que, em vista de seus particularmente elevados niveis médios de remuneração, considerados assim como implicitamente suficientes para ocorrer às despesas de sustento da familia, não enveredou por êsse caminho.

E a Brasil? Não podemos nos orgulhar muito da solução que vigota entre nós neśse particular.

Com base no Decreto-lei n 3.200 de 19 de abril de 1941 e, particularmente, em consonância com os dispositivos do art. 29 (regulamentado pelo Decreto $n^{\circ} 12.229$, de 22 de abril de 1943) foi apenas criado o abono familiar em favor das famílias numerossíssimas (com, pelo menos, 8 filhos menores), custeado pela União, Estados e Municipios, que beneficia as famílias de rendimentos baixos (cuja «retribuição fôr inferior ao dôbro do salário-mínimo»), sendo que não se logrou reajustar o valor dêsse benefício ( 100 cruzeiros por 8 filhos e 20 cruzeiros por filho excedente a êste número) que, assim, nesse meio tempo, perdeu quase integralmente seu antigo valor aquisitivo.

Quanto à amplitude e ao valor dêsse benefício, êle fica muito aquém do «salário familia» garantido aos servidores públicos.

Em vista do lamentável fracasso dessa providência legislativa que resultou da notória situação crítica dos orçamentos públicos, a Igreja levantou, 
nestes últimos anos, a idéia de constituição das caixas de compensação familiar, idéia essa decerto merecedora da maior atenção, possivelmente em conexão com as realizações dos Serviços Sociais Patronais (SESI e SESC).

A razão de ser das medidas de proteção sócio-econômica à família das camadas de rendimentos baixos não pode ficar sujeita, nas condições específicas do Brasil, a contestação alguma. A crise de família, a influência perturbadora que sofre seu antigo conceito tradicional no panorama agitado da vida urbana e a fraqueza dos laços maritais são fatos incontestáveis. Os altos indices de natalidade e a melhoria dos coeficientes de sobrevivência infantil contribuíram para aumentar a composição da familia, cujo vulto fica, aliás, evidenciado pelo surpreendentemente elevado número dos beneficiados pelo abono familiar às familias numerosas, com, pelo menos, oito filhos menores. E, por sua vez, as dificuldades criadas pela alta permanente dos preços de todos os bens, provocada pelo forte surto inflacionário, agravam ainda muito mais a situação econômica da família proletária.

Como já resulta das considerações anteriores, o abono familiar pode servir, alternativa ou cumulativamente, para o consecução de dois objetivos de natureza diferente: para fomentar a natalidade (orientação demográfica) ou para fortalecer a posição econômica da familia (orientação social).

Analisando-se as realizações legislativas dedicadas a essa matéria não é impossivel tentar averiguar tal ou qual orientação que as inspire. Quando se concede sobretudo prêmios pagos de uma vez só sob a forma de capital pelo casamento, ou, com maior freqüência, pelo nascimento do filho (solução a que dá ênfase tôda partícular, por exemplo, a legislação soviética), pode se assumir que se tem em vista a contribuição preponderante dessas. vantagens para fins populacionais. Ao passo que em vista da distribuição dos respectivos benefícios sob a forma de prestações periódicas de caráter alimentar: abono familiar pròpriamente dito, é justo assumir que a legislaşão obedece, antes, aos objetivos sociais.

Evidentemente, tal classificação das legislações existentes nessa matéria tem caráter um tanto arbitrário. Acresce que a sua atuação real e efetiva pode divergir de seus propósitos nominais, de sua justificação filosófica.

Seja como fôr, nas condições do Brasil, com a taxa de crescimento anual igual a, mais ou menos, $2,4 \%$, os objetivos sociais e econômicos e os relacionados especificamente com a defesa da familia têm que relegar a ụ̣n lugar secundário os propósitos de natureza demográfica que parecem carecer de justificativa suficiente. Basta assinalar o problema aflitivo de «desemprêgo inicial», das crescentes dificuldades que encontra a absorção pela economia de trabalho dos numerosos contingentes de jovens e adolescentes em busca do primeiro emprêgo - reflexo indisfarçável das fortes pressões populacionais - para tornar bem patente que não precisamos de incentivos artificiais de fomento da natalidade, mas, sim, das providências: higiênicas e educacionais de amparo à nova geração, conjugadas às realizações construtivas de proteção sócio-econômica à familia, preconizadas 
com muita razão pela alta hierarquia nacional da Igreja, e pleiteadas, de um modo particular, em vários pronunciamentos salutares da Conferência dos Bispos.

Ultrapassaria os limites dêsse trabalho a análise pormenorizada da orientação mais recomendável dessas realizações que, como é natural, deveriam descansar, por um lado, em firmes fundamentos de cálculos, baseados na interpretação exata da nossa bioestatística e, por outra parte, na análise de todos os aspectos da economia distributiva. 